\title{
Improvement in the Prognosis of Esophageal Cancer Patients Treated by Surgery Alone (the Sweet Approach) in a High Volume Center Between 1970 and 2008 - A Retrospective Analysis of 5349 Cases
}

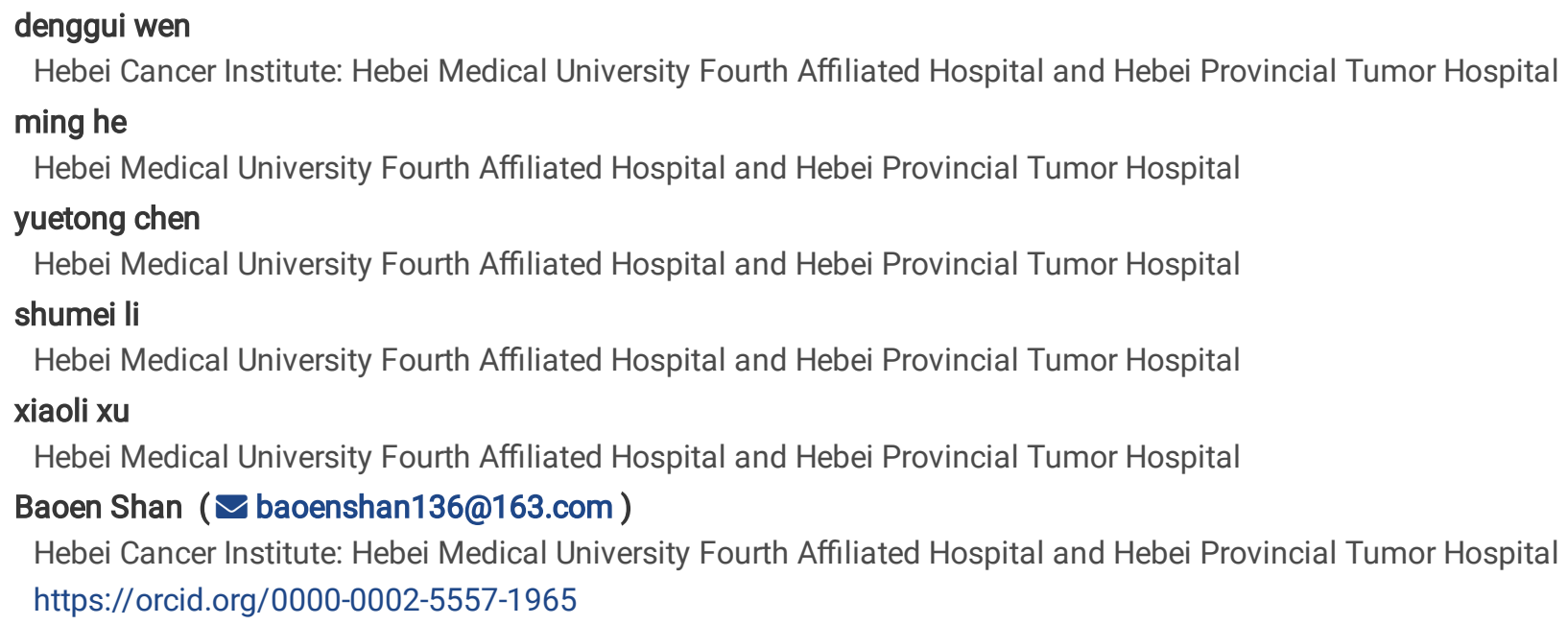

\section{Research}

Keywords: Carcinoma of the esophagus, Surgical improvement, Left thoractomy with limited two field lymphadenectomy (the Sweet procedure), Postoperative complication, Operative mortality, Five-year survival rate

Posted Date: July 19th, 2021

DOI: https://doi.org/10.21203/rs.3.rs-695883/v1

License: @ (i) This work is licensed under a Creative Commons Attribution 4.0 International License. Read Full License 


\section{Abstract}

Backgrounds: Worldwide the largest number of esophageal cancer surgery is performed in China and left thoractomy with limited lymphadenectomy (the Sweet approach) used to be the main surgical procedure before 2010. However the prognosis associated with this procedure had improved or not remains unanswered, duo to frequent lost to follow-up of patients operated since 1990.

Methods: Using data of 5349 patients treated by surgery alone (Sweet) in a high volume center in 26 years (for which lost to follow-up $<10 \%$, we analyzed 5-year survival rates according to 1970-1979, 1980-1989, 1990-1994, and 2008 in relation to clinicopathological characteristics and technique development.

Results: Both the rate of postoperative complication and of 3-month mortality decreased significantly $(11.4 \%, 9.7 \%, 8.9 \%, 5.2 \%$, $P<0.01 ; 6.0 \%, 5.4 \%, 3.3 \%, 3.1 \%, P<0.05)$, but the death rate of surgical complications remained unchanged $(52.9 \%, 55.2 \%, 56.9 \%$, $59.4 \%, P>0.38)$. The proportion of patients without lymph node metastasis increased significantly $(30.9 \%, 31.0 \%, 35.5 \%$ to $52.9 \%$, $P<0.001)$. The 5 -year survival rate increased significantly $(32 \%, 35 \%, 38 \%, 43 \%, P<0.000)$ albeit a limited number of lymph node retrieved (median: 4.0, 4.0, 4.0, 5.0, $P>0.18)$. Multivariate Cox regression analysis identified pTNM stage $(P<0.001)$, postoperative complications $(P<0.001)$, lymph node metastasis $(P<0.001)$, surgery year $(P P<0.01)$, and age $(P<0.05)$ as independent significant prognostic factors.

Conclusion: The prognosis of esophageal carcinoma patients treated by surgery alone (Sweet approach) had improved from 19702008. Our data suggests that this improvement is due mainly to early diagnosis and reduced postoperative complication by experienced hands at high volume centers.

\section{Introduction}

According to GLOBACAN 2018, 572034 incident cases and 508585 deaths of esophageal cancer were estimated as having occurred in 2018 in China, constituting $53.7 \%$ and $55.7 \%$ of the world's total. [1] Surgery is the main treatment modality. This is especially true in northern central China where both the incidence and mortality rate of esophageal cancer have been estimated to be the world's highest. [2-4]In the early 1950s, a public cancer center with high volume surgical capacity was established in each of the four provinces of Henan, Hebei, Shanxi, and Shandong to provide surgical treatment. Regarding the surgical approach used, before esophagectomy through the right thoracic approach with three field lymphadenectomy became popular during the late 2000s as supported by the Chinese Society of Esophageal Cancer, Chinese Anti-Cancer Association, [5] most esophagectomy performed at high volume centers had been through the left thoracic approach with incomplete two field lymphadenectomy (Sweet). [6] The department of Thoracic Surgery at the $4^{\text {th }}$ Hospital of Hebei Medical University (Hebei Provincial Cancer Center) alone had performed 24653 cases of esophagectomy/esophagogastrectomy by this procedure with curative intent from 1952 to 2009, exclaiming the largest number found with any single institute. [3,4] A series of large numbered studies have been published by these high volume centers reporting increasing rates of resectability and decreasing rates of postoperative complication associated with the Sweet approach. [2-5] However doubt remains as to whether the long term survival rate has improved. [5] A main reason for this is that starting from 1990, follow-up of patients after discharge has become more and more difficulty as a result of growing doctor-patient distrust caused by the increased profit-seeking behavior in the medical sector. The high rate of lost to follow-up has reduced the credibility of survival rates estimated. [7]

To investigate if there is any improvement in long term survival associated with patients treated by surgery alone (Sweet), we actively re-contacted family of patients operated since 1990 and succeeded in obtaining complete survival data for the patients operated from 1990-1994 and in 2008. Then together with previous cohort data for patients resected from 1970-1989, we analyzed five year survival rates according to the four time periods of 1970-1979, 1980-1989, 1990-1994, and 2008 in relation to the trend of clinicopathological factors and technique development.

\section{Methods}

\subsection{Patients eligibility}

Only esophageal cancer patients treated by surgery alone using the Sweet approach at the Department of Thoracic surgery at the Hebei Province Cancer Center were eligible for analysis. Since complete follow-up data were obtained only for patients resected from 
1970-1994 and in 2008 (with lost to follow-up rate below 10\%), patients were recruited on the basis that they were operated in these 26 calendar years. Because in these years the Sweet approach had been the dominating surgical procedure used at the Department, and multidisplinary therapy (surgery plus neoadjuvant or adjuvant chemotherapy, radiotherapy, chemoradiotherapy, or immunotherapy) was not routinely offered at that time, $82.9 \%$ of the operated patients $(5349 / 6453)$ were eligible for analysis. Patients excluded included: (1). 43 patients with $\mathrm{p}_{\text {is }}$ tumor (UICC/AJCC $7^{\text {th }}$ stage 0 ) and 143 patients with ${ }_{p} T_{1 a}$ (Tumor invading the lamina propria, UICC/AJCC $7^{\text {th }}$ stage I $\mathrm{a}_{\mathrm{a}}$ )for reasons as stated in literature [8]; (2). 809 patients who had been offered neoadjuvant or adjuvant chemotherapy, radiotherapy, or immunotherapy in addition to surgery for reasons to eliminate confounding by advances in these multimodality therapy; (3). 13 patients accepted transhiatal esophagectomy, and 90 patients undergone esophagectomy through a right thoractomy were also excluded. (4). 6 patients with cervical esophageal cancer were excluded because these tumors are biologically different from their thoracic counterpart and were operated in collaboration with surgeons of the laryngology Department. Finally a total of 5349 patients with carcinoma of the thoracic esophagus undergoing esophagectomy through left thoractomy with curative intent were included (1970-1979 ( $N=1505), 1980-1989(\mathrm{~N}=1840), 1990-1994(\mathrm{~N}=1387)$, and $2008(\mathrm{~N}=617))$. Surgery was performed by 60 chief thoracic surgeons spanning 3-4 consecutive generations. By the end of 2017 any chief surgeon in the department has performed at least a minimum of 100 esophagectomies. Surgical techniques used were introduced in detail by a previous study.[4]

\subsection{Clinicopathological data}

Detailed data including patient demographic characteristics, clinic symptoms, diagnostic workup by esophagography, CT, endoscopy and biopsy, endoscopic ultrasound, balloon cytology, surgical exploration, postoperative pathological examination of depth of tumor invasion $(T)$, degree of differentiation, lymph node invasion $(N)$, distant metastasis $(M)$, occurrence of surgical complication and hospital deaths were extracted from patient's chart. A dataset was constructed using the SPSS (IBM 20.0) data editor. Tumor staging was performed according to the UICC/AJCC $7^{\text {th }} \cdot[8]$

\subsection{Follow-up after discharge}

After discharge, patients are told to visit the surgeon at the outpatient clinic every 3 month during the first 3 year and then every half a year afterwards for surveillance of surgical results and recurrence. During visit, esophagography, CT, laboratory examination were prescribed and necessary intervention procedure was performed to treat complication. In addition to period clinic visit by the patient personally, the patient or his/her family is also contacted every half a year through letter or telephone by a special follow-up group set up by the Department of Thoracic Surgery at the cancer center. This communication with the patient or his/her family is continued year after year. If response from the patient stopped, an active visit or call was made by the follow-up group to the family to confirm the survival status. From 1970-1989, every year the lost to follow-up rate was less than 10\%. But since 1990, the rate began to exceed $10 \%$. To reduce lost to follow-up, we actively visited the family of each non-response patient and if again failed, we checked household record at the Room of Vital Statistics in the Local Police Station to verify the survival status. By this way, we collected complete survival data for patients operated in the year from 1990-1994 and in 2008.

\subsection{Statistical Analysis}

The end point for follow-up was to 31, December 2017. The minimum time of follow-up for censored patient had been 9 years. The SPSS statistical package, version 20.0 for Windows (IBM, Armonk, NY, USA) was used to construct data sets and perform statistical analyses. The significant level of difference between means of normally distributed continuing variables was tested by $T$ Test, that between distribution unknown variables was tested by the Mann-Whitney Test, and that between rates of qualitative variables was tested by the Chi-square Test. One-way analysis of variance (ANOVA) was employed to test the difference in continuous variables over the four time periods and the linear trend. The increasing trend in the rates of resectability and postoperative survival and the decreasing trend in the rates of postoperative complication and operative mortality according to the four time periods were examined by linear-by-linear association of the Pearson chi-square test. Five-year survival rates for large sample of patients $(N>=100)$ were calculated by Life-table methods and the differences between time period were tested according to Gehan Test. For small sample of patients in subgrouped analysis, 5-year survival rates were calculated by the Kapalan-Meier method and the differences between time periods were tested by the Log-rank test. $P<0.05$ was considered as statistically significant. When calculating survival rates, patients died of surgical complications were included. 
To evaluate the effect of prognostic factors on survival of patients with surgically resectable esophageal cancer (degree of residual tumor: R0 , R1 , R2), multivariate analysis was performed using Cox regression model. Variables found to be significant in univariate analysis were included, such as sex, age, decade of surgery (1970s vs. 1980s vs. 1990-94 vs. 2008), pTNM stage (『B , 『A, 『B , III A, III B , IIIC (excluding T4bN3)), postoperative complication (absent vs. present), averaged number of lymph nodes harvested, percent of lymph nodes metastasized. For variables found to be related to prognosis by multivariate Cox regression, their trend over the four decades were assessed.

\subsection{Ethics approval and consent to participate}

The study was approved by the Institutional Ethics Review Board of 4th Hospital of Hebei Medical University (20160001). Informed consent to participate was obtained from study participants and/or their family.

\subsection{Consent to publication}

There are no details/images/videos relating to an individual person reported within the manuscript. Consent to publication nonapplicable.

\section{Results}

\subsection{General demographic and clinicopathologic Characteristics}

Of the 5349 esophageal cancer patients treated by surgery alone with the Sweet approach, the male to female sex ratio was $2.1: 1$ and the mean age at diagnosis was 53.3 years old. Regarding tumor location of esophageal cancer, the tumor was in the upper third in 225 of 5349 cases (4.2\%), in the middle third in $3969(74.2 \%)$, and in the lower third in $1155(21.6 \%)$. Histologically $98.6 \%$ of esophageal cancer is squamous cell carcinoma, of which $57.1 \%$ were poorly differentiated.

\subsection{Resectability}

3.2.1. The overall resectability rate with the 5349 cases of esophageal cancer undergoing resection with curative intent was $96.0 \%$ $(5136 / 5349)$. The resectability rates increased significantly over the four time periods $(90.7 \%, 97.1 \%, 98.7 \%, 99.8 \%, P<0.01)$. (Table 1$)$

3.2.2. The mean age of esophageal cancer patients undergone resection increased significantly $(51.6,52.0,53.7,60.0$ years old, $P<0.01)$; the proportion of patients in preoperative co-morbidity with cerebral or cardiovasicular disease increased significantly $(0.4 \%$, $2.6 \%, 3.5 \%, 13.3 \%, P<0.01)$; the proportion of esophageal cancer patients with tumor located in the upper third of the thoracic esophagus increased significantly $(1 \%, 1.2 \%, 3.4 \%, 5.4 \%, P<0.01)$.

\section{3. Lymph node metastasis and dissection}

\subsubsection{Proportion of lymph node metastasis}

The proportion of patients with lymph node metastasis by post operative pathological examination decreased significantly $(69.1 \%$, $69.0 \%, 64.5 \%, 47.1 \%, P<0.001)$. Or according to the UICC/AJCC $7^{\text {th }}$ staging system, the proportion of patients with $P_{P} T N M$ stage $\mathbb{B}_{B}-\nabla_{A}$ disease increased significantly $(30.9 \%, 31.0 \%, 35.5 \%, 52.9 \%, P<0.001)$; in contrast, those with $\mathrm{III}_{\mathrm{C}}\left(\mathrm{T}_{4 \mathrm{~b}} \mathrm{~N}_{3}\right)$ - IV disease (surgically nonresectable) decreased significantly $(28.2 \%, 21.8 \%, 18.9 \%$ to $11.1 \%, P<0.001)$; however, the proportion of patients with advanced but still resectable lesion, e.g., in the stage of $\mathbb{B}_{B} / \mathrm{III}_{A} / \mathrm{III}{ }_{B} / \mathrm{III}$ C (excluding $\mathrm{T}_{4 \mathrm{~b}} \mathrm{~N}_{3}$ ), remained constant $(53.5 \%, 56.7 \%, 56.4 \%, 53.6 \%, P>0.25$, Fig 1).

\subsubsection{Number of lymph node harvested}

The average number of lymph nodes harvested in mediastinal and abdominal lymph node dissection increased significantly ( 3.93 , $4.03,4.51,5.07, P<0.001)$, but the median number of that increased non-significantly $(4.0,4.0,4.0,5.0, P=0.18)$ (Table 1$)$.

\subsection{Operative mortality}

Of the 5136 patients resected, 242 patients died within 90 days of surgery, for a 3-month mortality rate of $4.7 \%(242 / 5136)$. The 3month mortality rate decreased significantly over the four time periods, from $6.0 \%, 5.4 \%, 3.3 \%$ to $3.1 \%(P<0.01) .128$ patients died 
within 30 days of surgery, for a 1-month mortality rate of $2.5 \%$ (128/5136). The 1-month mortality rate also decreased significantly from $3.2 \%, 3.0 \%, 1.7 \%$ to $1.3 \%(P<0.01$, Table 1$)$.

\subsection{Postoperative complication}

\subsubsection{Postoperative complication}

Of the 5136 cases resected, postoperative complication occurred in $9.4 \%(483 / 5136)$. The rate decreased significantly over the four time periods, from $11.4 \%, 9.7 \%, 8.9 \%$ to $5.2 \%(P<0.01)$. Anastomotic leakage occurred in $3.1 \%(158 / 5136)$ and was the most common complication, and Pulmonary complication developed in $2.3 \%$ (119/5136) and was the second most common complication. Both rates decreased significantly over the four time period $(3.2 \%, 3.9 \%, 2.3 \%$ to $1.9 \%, P<0.05 ; 5.6 \%, 1.1 \%, 1.6 \%$ to $0.3 \%, P<0.01)$. However, the rate of cerebro or cardiavasicular complication increased significantly $(0.3 \%, 1.0 \%, 0.7 \%, 2.1 \%, P<0.05)($ Table 2$)$.

\subsubsection{Death rate of complication and anastomotic leakage}

In contrast to the decreasing rates of postoperative complication and operative mortality, the death rate of complication remained the same as $52.9 \%, 55.2 \%, 36.9 \%$, and $59.4 \%$ over the four time periods $(P>0.05)$ however\and so did the death rate of anastomotic leakage $(77.3 \%, 85.7 \%, 96.9 \%, 75.0 \%, P>0.05)$ (Table 2$)$.

\subsection{Improvement in five year survival rates}

The overall 5-year survival rate was $36 \%$ and the 5 -year survival rate progressed significantly from $32 \%, 35 \%, 38 \%$ to $43 \%(P<0.001)$ (Table 3, Fig 2). When the significance of improvement in 5-year survival rate between consecutive decades was tested, that from 1970s to 1980s and from 1980s to 1990-1994 were non-significant, but the progression from 1990-1994 to 2008 was significant (Table 3, Fig 2).

When improvement in 5-year survival over the four time periods was analyzed according to pTNM stage, significant improvement was observed only among patients in the stage of $\mathbb{X}_{B} / \mathbb{Z}_{A} / \mathbb{X}_{B} / I I I{ }_{A} / I I I_{B} / I I I_{C}$ (excluding $T_{4 b} N_{3}$ ) (Fig 3), not among patients in the stage of III $\left(\mathrm{T}_{4 \mathrm{~b}} \mathrm{~N}_{3}\right) / \mathrm{IV}$ (Fig 4).

\subsection{Multivariate Cox regression analyses}

Of the 7 demographic or clinicopathologic characteristics found to be significant by univariate Cox regression analysis, five were identified as significant independent prognostic factors by the backwards multivariate model. These were pTNM stage $(P<0.001)$, postoperative complications $(P<0.001)$, the percent of lymph node metastasized $(P<0.001)$, decade of surgery $(P<0.01)$, and the average age of the patients $(P<0.05)$.However, sex and the median number of lymph nodes harvested did not reached significant level as independent prognostic factor. Of the five significant prognostic factors, three had changed significant over the four decades; e g., pTNM stage and rate of postoperative complications decreased significantly (both $P<0.001$ ), but the average age of patients resected increased significantly $(P<0.05)$. Of note, the median number of lymph node retrieved was eliminated in step 2 backwards regression from significant prognostic factors (Table 4).

\section{Discussion}

It has been claimed that in China the long term survival of esophageal cancer patients treated by surgery alone has not improved during the past 60 years. [5]Reasons for this include late stage at diagnosis, relaxation of surgical indication, exclusive use of esophagectomy through the left thoracic approach with incomplete two field lymphadenectomy (Sweet).[2-5]However, lack of reliable follow-up data in high volume centers for patients operated during the 1990s and 2000s, as a result of growing hospital-patient distrust, has also contributed in causing the uncertainty.[7]

After excluding esophageal cancer patients who had undergone multimodality treatment, our present retrospective study found that from 1970s, 1980s, 1990-1994, to 2008, the 5-year survival rate of those patients treated by surgery alone had increased significantly from $32 \%, 35 \%, 38 \%$ and $43 \%(P<0.001)$. Together with a 5 -year survival rate of $23.5 \%$ previously reported for 1290 esophageal cancer cases resected between 1952-1973 (when adjuvant therapy was scarce) at the center,[9] our results suggest that significant improvement in long term survival has been associated with the Sweet approach from 1952-2008, just as that reported in Japan associated with the right thoractomy with three field lymphadenectomy. [10-17] Since we excluded those patients who had undergone 
multimodality treatment, survival improvement associated with the development of chemo/radio/immuno therapy was not the focus of present study.

Not only an increasing trend, the 5-year survival rates (35\%-38\%) of patients resected during the 1980s and 1990s associated with the Sweet approach in our center are also comparable to the rate reported by Ando (40\%) for 419 esophageal cancer cases resected from 1981-1995 at Keio University Medical School Hospital of Japan by the right thoracic approach with three field lymphadenectomy,[14] or are identical to that of $34.3 \%$ as reported by Isono $\mathrm{K}$ for a total of 1740 cases of esophageal cancer resected similarly at 35 Japanese centers between 1983-1989, [10] although in Isono's study hospital deaths due to severe surgical complication were excluded when calculating 5-year survival rates.

Esophagectomy through the right thoracic approach with three field lymphadenectomy was first introduced in 1983 at the Cancer Center of Ciba University Medical School of Japan. [10] Although this surgical approach carries a higher risk of operative complications such as injury of recurrent laryngeal nerves and is time-consuming, it is preferred over the Sweet approach because it provides excellent surgical exposure to the upper right mediastinal lymph nodes and ensures higher harvesting of suspected metastatic lymph nodes. [15] In Japan the approach was reported to have increased the 5 -year survival rate by $10 \%$ than the traditional Sweet approach. [10-17] It is convincing that a complete lymphadenectomy would have contributed significantly more than a limited one to the long term survival. In expectation of breakthrough in long term survival of esophageal surgery, right thoractomy with three field LND was rapidly accepted since it was introduced to China in the late 2000s. [15]

On the other hand, the Sweet procedure has been widely used in high volume cancer centers in China for more than 80 years. [6] It has the merits of shorter operation time, faster postoperative recovery, and reduced surgical complication. These advantages are supported by solid evidence from large surgical cohorts in northern central China. [18-21] In fact for operations as traumatic as transthoracic resection of esophageal cancer with 2 or 3 field lymphadenectomy, surgical complication or postoperative morbidity also affect postoperative survival.[22] In a multivariate Cox regression analysis of 419 esophageal cancer cases resected at Keio University Medical School Hospital of Japan, Ando reported that among the seven significant independent prognostic factors including gender, surgical year (1981-1987 vs. 1988-1995), depth of tumor invasion (T1b/T2/T3/T4), lymph node metastasis (N0/N1-3/N4-6/N7-), degree of residual tumor (R0/R1,R2), postoperative complication (none/non-lethal complication/lethal complication) and number of dissected mediastinal nodes, the effect of postoperative complication was the largest and was identical to that of lymph node metastasis (Relative risk and 95\% Cl 2.23 (1.78-2.80), $P<0.0001$ and 1.59 (1.34-1.89), $P<0.0001$ respectively).[14] In present study, although postoperative complication decreased significantly, death rate among patients with complication unchanged, suggesting prevention of surgical complication is very important.

Our Center in collaboration with the second Department of Surgery of Shinshu University Medical School of Japan performed a comparative study between esophagectomy through the Sweet approach with limited two field lymph node dissection (LND) vs. esophagectomy through the right thoracic approach with extensive two or three field LND in 1994. The results indicate that although lymph node harvesting is increased and more metastatic lymph nodes are found by extensive LND, it also carries a higher rate of surgical complications and a high operative mortality rate, and the stage-specific 5-year survival rates showed no significant difference (Table 5). The authors concluded that extended lymphadenectomy should be balanced to surgical safety to improve the long term survival. [23]

In a randomized prospective clinic trail by Li B et al of Shanghai Cancer Center of Fudan University published in 2017, disease-free survival (DFS) and overall survival (OS) were compared between the right thoractomy with extensive two field lymphadenectomy $(n=146)$ and left thoractomy with limited two field lymphadenectomy $(n=140)$. The number of median lymph node retrieved was significantly different (22 (17-33) vs. 18 (13-26), $P<0.001)$ ). The 3-year DFS rates were $62 \%$ vs. $52 \%(P=0.047)$ and the 3 -year OS rates were $74 \%$ vs. $60 \%$ ( $P=0.029)$ respectively. [24]However, a recent study in a high volume center (Henan Cancer Center) comparing the right $(n=202)$ and left thoracic approach esophagectomy $(n=235)$ found no significant difference in 5-year survival rate.[20] The Henan colleagues argued that the left approach as described in the Fudan trial might have been unrepresentative of a standard Sweet approach by experienced hands in high volume centers because the usual advantages in operation time, hospital stay and surgical complication are not apparent as compared to that in other Chinese studies. [18-21,25]Interestingly however, Henan colleagues not only demonstrated the usual advantages concerning surgical safety for the Sweet approach, the median number of lymph node retrieved by them with the left approach was no less than that with the right approach (median 21 (8-64) vs.26 (8-60), $P=0.708$ ). [20] The discrepancy between these two studies seem to suggest that both a minimum complication and a complete lymphadenectomy are mandatory for the improvement of long term survival, and currently in China regarding both there is room for improvement.

Page 6/14 
In Cox regression analyses, we found PTNM stage, postoperative complication, percent of lymph node metastasis and year of surgery were significant independent prognostic factors, but the median number of lymph node retrieved has not reached significant level. The result is understandable because the median number of lymph node retrieved at our center has not improved from 1970-2008. we consider the improvement in long term survival in present study is related to but not limited to following factors:

1. The proportion of patients with early cancer increased significantly over the four decades. This is possibly due to free population based screening programs organized by the government in endemic areas. Balloon cytology had been used between 1970-1990, and in recent years endoscopy with iodine staining and biopsy has become the main modality.

2. From 1952-2008, as image technique developed from esophagography, computed tomography (CT), endoscopy, positron emission tomography (PET), and ultrasound endoscope, disease staging became more and more accurate.

3. Between 1987 and 2009, the America Joint Commission on Cancer (AJCC)/ International Union against Cancer (UICC) have consecutively published the $1^{\text {st }}$ to $7^{\text {th }}$ edition of esophageal cancer staging manual which provided reliable evidence for choosing the correct surgery procedure. The manuals also enabled scientific assessment and comparison of the surgical results.

4. Improvement in surgical techniques such as choosing the neck as the site of esophagogastrostomy to increase the length of resection,[2-4] the increased use of stapled anastomoses since the late 1980s to reduce the rate of anastomotic leakage,[2-4] and development of advanced peri-surgical management by targeted nursing and nutritional support etc. [2-4]

The strength of present study lies in the large number of patients with complete follow-up data in 26 years after excluding those who undergone multimodality treatment in a high-volume thoracic cancer center, and the surgical experience built up since 1952. In addition, patients died of surgical complications were included when calculating the five year survival rates to reflect the influence of surgical complication.

A weak point of this study lies in the limited number of lymph node retrieved, which might have prevented accurate TNM staging. However, since we are focused on studying the increasing trend of long term survival without the contribution of a significantly increased lymph node dissection, the inadequate lymph node staging may not have biased the trend of overall long term survival.

In summary, by analyzing survival data of 5349 cases of esophageal cancer treated by surgery alone with the Sweet approach in 26 calendar years in a high volume center, we found significant improvement in the short and long term results from 1970-2008. Because the number of median lymph node retrieved at our center had remained 4-5 over the four periods and which is far from being adequate according to current standard, ${ }^{[26]}$ improvement in survival from 1970-2008 may have been derived largely from early diagnosis and reduced surgical complication by experienced hands with a high volume center. While the competence should be maintained, effort must be made to improve the extent of lymphadenectomy.

\section{Declarations}

\section{Ethics approval and consent to participate}

The study was approved by the Institutional Ethics Review Board of 4th Hospital of Hebei Medical University (20160001). Informed consent to participate was obtained from study participants and/or their family.

\section{Consent to publication}

There are no details/images/videos relating to an individual person reported within the manuscript. Consent to publication nonapplicable.

\section{Acknowledgment}

The authors are grateful to all colleagues involved in surgical treatment of esophageal cancer in The Fourth Hospital of Hebei Medical University, especially the dedicated surgeons at the Department of Thoracic Surgery of the hospital.

\section{Disclosure statement}


The authors declare that the research was conducted in the absence of any commercial or financial relationships that could be construed as a potential conflict of interest.

\section{Author Contributions}

All authors have made substantial contributions to the conception and design of the study. SB, WD, HM, CY, LS and XX led the study design. SB, WD, HM, CY, LS and XX made follow-up, abstracted medical charts, checked original diagnoses, staged tumors, constructed datasets, performed statistical analyses, and drafted manuscript. SB, WD, HM and CY contributed to writing and revising the manuscript. All authors have reviewed and approved the submission.

\section{Funding}

This work was partially supported by a grant for Key subject development for universities of Hebei Province (No.03276198D).

\section{Availability of data and materials}

The data set supporting findings of this paper will be provided upon request or uploaded online as suggested.

\section{References}

1. Bray F, Ferlay J, Soerjomataram I, Siegel RL, Torre LA, Jemal A. Global Cancer S. 2018: GLOBOCAN Estimates of Incidence and Mortality Worldwide for 36 Cancers in 185 Countries. CA CANCER J CLIN. 2018; 0:1-31. http://gco.iarc.fr/today/data/factsheets/populations/160-china-fact-sheets.pdf. doi: 10.3322/caac.21492. Epub 2018 Sep 12.

2. Huang G. Fundamental experience of thoracic surgery in China over half a century. Chinese J Oncology 2007;29(10):795 - 97. (in Chinese). PMID: 18396698.

3. Ping Y. Experience and long term results of surgical treatment of esophageal and gastric cardia cancer between 1952-2005 in a high volume Chinese center. Education book of the 5th Chinese conference of oncology. September 2008. Shijiazhuang, China. (in Chinese).

4. Liu J, Wang Q, Hou J. Surgical treatment for cancer of the oesophagus and gastric cardia in Hebei, China. British J Surgery. 2004;91:90-8. doi:10.1002/bjs.4402.

5. Chinese Society of Esophageal Cancer, Chinese Anti-Cancer Association. Surgical Strategy for Treatment of Resectable Esophageal Cancer. Clinical Practice Guidelines for the Diagnosis and Treatment of Esophageal Cancer. Press of Chinese Union Medical University. Beijing, 2011.3. pp. 39-51.

6. Gao S, Liu Y, Geng Q, Zhao Y, Wang J. Development history of thoracic surgery in China. Chin J Surg2015; 53:27-32. doi: 10.3760/cma.j.issn.0529- 5815.2015.01.008.

7. Wen $D$, Zhao X, Wei L, Cui D, Lin M, Xu L, et al. Reducing the rate of lost to follow-up after discharge to enhance the follow-up data quality of surgically treated esophageal and gastric cardia cancer patients. Chinese J Medical Chart. 2005;6(4):10-1..(in Chinese).

8. Edge S, Byrd D, Compton CC et al, editors. AJCC Cancer Staging Manual. 7th ed. New York: Springer; 2009.

9. Wu Y, Chen P, Fang J, Lin S. Surgical Treatment of Esophageal Carcinoma. The American Journal Surgery. 1980;139:805-9. doi:10.1016/0002-9610(80)90386-4.

10. Isono K, Sato H, Nakayama K. Results of nationwide study of the three field lymph node dissection of esophageal cancer. Oncology. 1991;48:411-20. doi:10.1159/000226971.

11. Watanabe $\mathrm{H}$. The problem of cervical -thoracic-abdominal (3 field) lymphadenectomy for thoracic esophageal cancer. Ann Thorac Surg. 1995;59:349-53.

12. Tsurumaru $\mathrm{M}$, Udagawa $\mathrm{H}$, Kajiyama $\mathrm{Y}$. Rational extent of lymphnode dissection for carcinoma of the lower third of the thoracic esophagus of T2 or T3 stage with abdominal lymph node metastasis. Nippon Gekkai Zasshi. 1997;98:755-60. PMID: 9370135.

13. Akiyama H, Tsurumaru M, Udigawa H, et al. Esophageal Cancer. Curr Prob Surg. 1997;34:796-806. doi:10.1016/s00113840(97)80015-9. 
14. Ando N, Ozawa S, Kitagawa Y, Shinozawa Y, Kitajima M. Improvement in the Results of Surgical Treatment of Advanced Squamous Esophageal Carcinoma During 15 Consecutive Years. Ann Surg. 2000;232:225-32. doi:10.1097/00000658200008000-00013.

15. Fang W, Kato H, Chen W, Tachimori Y, Igaki H. Comparison of surgical management of thoracic esophageal carcinoma between two referral centers in Japan and China. Jpn J Clin Oncol. 2001;33:203-8. doi:10.1093/jjco/hye043.

16. Isono K, Koide Y. Multimodalitytreatment of thoracic esophageal carcinoma. Gan To Kagaku Ryoho. 1993;20(9):1147-53. PMID: 8333742.

17. Shimada H, Okazumi S, Matsubara H, Shiratori T, Akutsu Y, Nabeya Y, et al. Long-term Results after Dissection of Positive Thoracic Lymphnodes in Patients with Esophageal Squamous Cell Carcinoma. World J Surg. 2008;32:255-61. doi:10.1007/s00268-007-9213-1. Epub 2007 Dec 7.

18. Ma J, Zhan C, Wang L, Jiang W, Zhang Y, Shi Y. The sweet approach is still worthwhile in modern esophagectomy. Ann Thor Surg. 2014;97:1728-33. doi:10.1016/j.athoracsur.2014.01.034.

19. Zhang H, Wang J, Wang W, Zhou L, Chen J, Yang B. A metaanalysis of esophagectomy: the comparative study of Ivor-Lewis operation and Sweet operation. Zhonghua wei chang wai ke za zhi. 2014;17:892-7. doi:10.3760/cma.j.issn.16710274.2014.09.012.

20. Zheng Y, Li Y, Liu X, Zhang R, Sun H, Xing W. (2020) Right Compared With Left Thoracic Approach Esophagectomy for Patients With Middle Esophageal Squamous Cell Carcinoma. Front. Oncol. 2020;10:536842.doi:10.3389/fonc.2020.536842.

21. Ma Q, Liu W, Long H, Rong T, Zhang L, Lin Y, Ma G. Right versus left transthoracic approach for lymph node-negative esophageal squamous cell carcinoma. Journal of Cardiothoracic Surgery. 2015;10:123. doi:10.1186/s13019-015-0328-4.

22. Mariette C, Piessen G. Oesophageal cancer: How radical should surgery be? Euro J Surg Oncol. 2012;38:210-3. doi:10.1016/j.ejso.2011.12.022.

23. Adachi W, Koike S, Nimura Y, Koide N, lida F, Du X, Ping Y, He M, Chen L, Zhang D, Zhang H. Clinicopathologic Characteristics and Postoperative Outcome in Japanese and Chinese Patients with Thoracic Esophageal Cancer. World J Surg. 1996;20:332-6. doi:10.1007/s002689900053.

24. Li B, Hu H, Zhang Y, et al. Extended Right Thoracic Approach Compared With Limited Left Thoracic Approach for Patients With Middle and Lower Esophageal Squamous Cell Carcinoma: Three-year Survival of a Prospective, Randomized, Open-label Trial. Ann Surg. 2018;267:826-32. doi:10.1097/SLA.0000000000002280.

25. Mu J, Gao S, Xue Q, Mao Y, Wang D, Zhao J, et al. The impact of operative approaches on outcomes of middle and lower third esophageal squamous cell carcinoma. J Thor Dis. 2016;8:3588-95. doi:10.21037/jtd.2016.12.42 ].

26. Li H, Fang W, Yu Z, Mao Y, Chen L, He J, et al. on behalf of The Society of Esophageal Tumor, Chinese Anti-Cancer Association. Chinese expert consensus on mediastinal lymph node dissection in esophagectomy for esophageal cancer (2017 edition). J Thorac Dis.2018;10(4):2481-9. doi: 10.21037/ jtd.2018.03.175.

\section{Tables}


Table 1

Rate of respectability, operative mortality, average number of lympha node dissected and rate of metastasis with esophageal cancer from 1970-2008

\begin{tabular}{|c|c|c|c|c|c|c|c|c|}
\hline Periods & $\begin{array}{l}\text { No } \\
\text { operated }\end{array}$ & $\begin{array}{l}\text { No } \\
\text { Resected } \\
(\%)\end{array}$ & $\begin{array}{l}\mathrm{R}_{0} \\
(\%)\end{array}$ & $\begin{array}{l}\text { Average lymph } \\
\text { nodes harvested } \\
\text { (n) }\end{array}$ & $\begin{array}{l}\text { Median lymph } \\
\text { nodes harvested } \\
\text { (n) }\end{array}$ & $\begin{array}{l}\% \text { of metastasis } \\
\text { among the } \\
\text { harvested (\%) }\end{array}$ & $\begin{array}{l}\text { No died } \\
\leq 3 \\
\text { month } \\
(\%)\end{array}$ & $\begin{array}{l}\text { No died } \\
\leq 1- \\
\text { month } \\
(\%)\end{array}$ \\
\hline $\begin{array}{l}1970- \\
1979\end{array}$ & 1505 & $\begin{array}{l}1365 \\
(90.7)\end{array}$ & 74.5 & 3.93 & $4(1-12)$ & 0.21 & $82(6.0)$ & $43(3.2)$ \\
\hline $\begin{array}{l}1980- \\
1989\end{array}$ & 1840 & $\begin{array}{l}1786 \\
(97.1)\end{array}$ & 84.1 & 4.03 & $4(1-23)$ & 0.21 & $96(5.4)$ & $54(3.0)$ \\
\hline $\begin{array}{l}1990- \\
1994\end{array}$ & 1387 & $\begin{array}{l}1369 \\
(98.7)\end{array}$ & 89.6 & 4.51 & $4(1-23)$ & 0.20 & $45(3.3)$ & $23(1.7)$ \\
\hline 2008 & 617 & $\begin{array}{l}616 \\
(99.8)\end{array}$ & 97.1 & 5.07 & $5(2-20)$ & 0.19 & $19(3.1)$ & $8(1.3)$ \\
\hline Total & 5349 & $\begin{array}{l}5136 \\
(98.0)\end{array}$ & 84.6 & 4.26 & $4(1-23)$ & 0.20 & $242(4.7)$ & $128(2.5)$ \\
\hline
\end{tabular}

Table 2

Rate of postoperative complication and the associated death rate from 1970-2008 with esophageal cancer

\begin{tabular}{|llllllll|}
\hline Periods & $\begin{array}{l}\text { No } \\
\text { resected }\end{array}$ & $\begin{array}{l}\text { No with } \\
\text { complication(\%) }\end{array}$ & $\begin{array}{l}\text { Anastomotic } \\
\text { leakage(\%) }\end{array}$ & $\begin{array}{l}\text { Pulmonary } \\
\text { complication(\%) }\end{array}$ & $\begin{array}{l}\text { Cerebro } \\
\text { cardiavasicular } \\
\text { complication(\%) }\end{array}$ & $\begin{array}{l}\text { Death rate of } \\
\text { complication(\%) }\end{array}$ & $\begin{array}{l}\text { Death rate } \\
\text { of } \\
\text { anastomotic } \\
\text { leakage(\%) }\end{array}$ \\
\hline $\begin{array}{l}1970- \\
1979\end{array}$ & 1365 & $155(11.4)$ & $44(3.2)$ & $76(5.6)$ & $4(0.3)$ & $82(52.9)$ & $34(77.3)$ \\
\hline $\begin{array}{l}1980- \\
1989\end{array}$ & 1786 & $174(9.7)$ & $70(3.9)$ & $19(1.1)$ & $18(1.0)$ & $96(55.2)$ & $60(85.7)$ \\
\hline $\begin{array}{l}1990- \\
1994\end{array}$ & 1369 & $122(8.9)$ & $32(2.3)$ & $22(1.6)$ & $10(0.7)$ & $45(36.9)$ & $31(96.9)$ \\
\hline 2008 & 616 & $32(5.2)$ & $12(1.9)$ & $2(0.3)$ & $13(2.1)$ & $19(59.4)$ & $9(75.0)$ \\
\hline 0
\end{tabular}

Table 3

Five-year survival rate and median survival months after resection of esophageal cancer from 1970-2008

\begin{tabular}{|llll|}
\hline Time periods & No. resected & 5-year survival rate (\%) & Median survival (months) \\
\hline $1970-1979$ & 1365 & 32.0 & 27.2 \\
\hline $1980-1989$ & 1786 & 35.0 & 27.8 \\
\hline $1990-1994$ & 1369 & 38.0 & 29.6 \\
\hline 2008 & 616 & 43.0 & 35.9 \\
\hline Total & 5136 & 36.0 & 29.0 \\
\hline
\end{tabular}


Supplement A. P-value for paired comparison of 5-year survival rates of esophageal cancer operated between time periods

\begin{tabular}{|lllll|}
\hline & $1970-1979$ & $1980-1989$ & $1990-1994$ & 2008 \\
\hline $1970-1979$ & & 0.441 & 0.05 & 0.000 \\
$1980-1989$ & 0.441 & & 0.101 & 0.000 \\
$1990-1994$ & 0.05 & 0.101 & & 0.045 \\
\hline 2008 & 0.000 & 0.000 & 0.045 & \\
\hline
\end{tabular}

Table 4

Multivariate analysis of prognostic factors of esophageal cancer by backwards conditional Cox regression

\begin{tabular}{|c|c|c|c|c|c|}
\hline Steps & Variable & $\begin{array}{l}\text { Regression } \\
\text { Coefficient }\end{array}$ & $\begin{array}{l}\text { Relative risk } \\
(95 \% \mathrm{Cl})\end{array}$ & $\begin{array}{l}\text { P-value by Wald } \\
\text { test }\end{array}$ & Trend \\
\hline \multirow{7}{*}{$\begin{array}{l}\text { Step } \\
1\end{array}$} & Sex & -0.37 & $0.89-1.04$ & 0.362 & 0.35 \\
\hline & Age & 0.102 & $1.06-1.16$ & 0.000 & $\begin{array}{l}\mathrm{P}< \\
0.001\end{array}$ \\
\hline & Postoperative complication (present/absent) & 0.689 & $1.74-2.28$ & 0.000 & $\begin{array}{l}\mathrm{P}< \\
0.001\end{array}$ \\
\hline & Decade of surgery & -0.022 & $0.94-0.99$ & 0.042 & \\
\hline & $\begin{array}{l}\text { TNM stage }\left(\mathbb{\bigotimes}_{B} \text { or } \mathbb{A}_{A} \text { vs. } \mathbb{B}_{B} \text { or III }{ }_{A} \text { or III }{ }_{B} \text { or } I I I_{C}\right. \\
\left.\text { (excluding } T_{4 b} N_{3}\right) \text { ) }\end{array}$ & 0.805 & $2.04-2.45$ & 0.000 & $\begin{array}{l}P< \\
0.001\end{array}$ \\
\hline & Median No lymph node retrieved & -0.003 & $0.98-1.02$ & 0.742 & $\begin{array}{l}\mathrm{P}< \\
0.001\end{array}$ \\
\hline & Percent of lymph nodes metastasized (\%) & 0.670 & $1.75-2.18$ & 0.000 & $\begin{array}{l}P= \\
0.26\end{array}$ \\
\hline \multirow{6}{*}{$\begin{array}{l}\text { Step } \\
2\end{array}$} & Sex & -0.036 & $0.89-1.04$ & 0.371 & 0.35 \\
\hline & Age & 0.102 & $1.06-1.16$ & 0.000 & $\begin{array}{l}P< \\
0.001\end{array}$ \\
\hline & Postoperative complication (present/absent) & 0.689 & $1.74-2.28$ & 0.000 & $\begin{array}{l}P< \\
0.001\end{array}$ \\
\hline & Decade of surgery & -0.023 & $0.94-0.98$ & 0.04 & \\
\hline & 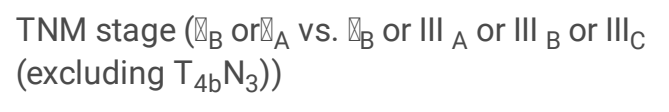 & 0.804 & $2.04-2.45$ & 0.000 & $\begin{array}{l}P< \\
0.001\end{array}$ \\
\hline & Percent of lymph nodes metastasized (\%) & 0.673 & $1.76-2.18$ & 0.000 & $\begin{array}{l}P= \\
0.26\end{array}$ \\
\hline \multirow[t]{5}{*}{$\begin{array}{l}\text { Step } \\
3\end{array}$} & Age & 0.102 & $1.06-1.16$ & 0.03 & $\begin{array}{l}P< \\
0.001\end{array}$ \\
\hline & Postoperative complication (present/absent) & 0.691 & $1.74-2.28$ & 0.000 & $\begin{array}{l}\mathrm{P}< \\
0.001\end{array}$ \\
\hline & Decade of surgery & -0.024 & $0.94-0.97$ & 0.01 & \\
\hline & $\begin{array}{l}\text { TNM stage }\left(\mathbb{\Xi}_{B} \text { or } \mathbb{A}_{A} \text { vs. } \mathbb{\Xi}_{B} \text { or } I I I_{A} \text { or } I I I_{B} \text { or } I I I_{C}\right. \\
\left.\text { (excluding } T_{4 b} N_{3}\right) \text { ) }\end{array}$ & 0.805 & $2.04-2.45$ & 0.000 & $\begin{array}{l}\mathrm{P}< \\
0.001\end{array}$ \\
\hline & Percent of lymph nodes metastasized (\%) & 0.672 & $1.76-2.18$ & 0.000 & $\begin{array}{l}P= \\
0.26\end{array}$ \\
\hline
\end{tabular}


Table 5. Comparison of surgical technique and results between $4^{\text {th }}$ Hospital of Hebei Medical University, China and Shinshu University Hospital, Japan

\begin{tabular}{|c|c|c|}
\hline Surgical techniques \& results & $\begin{array}{l}\text { Shinshu group }(n=140) \text { operated between } \\
1981-1991\end{array}$ & $\begin{array}{l}\text { Hebei group }(n=1164) \text { operated btw } \\
1985-1989\end{array}$ \\
\hline Esophagectomy \& anastomosis & $\begin{array}{l}\text { Right thoractomy \& laparatomy \&Cervical } \\
\text { incision }\end{array}$ & Left thoractomy \&Diaphragm incision \\
\hline Lymph node dissection & Radical two or three field dissection & $\begin{array}{l}\text { Standard dissection of thoracic \& } \\
\text { abdominal nodes }\end{array}$ \\
\hline $\begin{array}{l}\text { Averaged duration of operation } \\
\text { (hours) }\end{array}$ & 7 & 3.5 \\
\hline \multicolumn{3}{|l|}{ Nodal metastasis by $p_{\mathrm{p}} \mathrm{T}(\%)$} \\
\hline pT1 & 16.0 & 7.0 \\
\hline pT2 $2^{\star *}$ & 48.0 & 23.0 \\
\hline pT3 $3^{\star *}$ & 66.0 & 38.0 \\
\hline pT4 & 100.0 & 43.0 \\
\hline$A l I^{\star \star}$ & 50.0 & 33.0 \\
\hline 30-day operative mortality $(\%)^{\star *}$ & 4.6 & 1.8 \\
\hline \multicolumn{3}{|l|}{ Postoperative complication (\%) } \\
\hline Anastomotic leakage ** & 23.1 & 3.4 \\
\hline Recurrent nerve palsy ${ }^{\star *}$ & 23.1 & 0.4 \\
\hline Pulmonary complication ** & 17.6 & 1.5 \\
\hline Chylothorax ** & 0.0 & 0.7 \\
\hline \multicolumn{3}{|l|}{$\begin{array}{l}\text { 5-year survival rate (\%) by } \text { p TNM } \\
\text { (UICC 4th) }\end{array}$} \\
\hline I & 80.7 & 92.6 \\
\hline $\mathrm{II}_{\mathrm{a}}$ & 37.9 & 53.9 \\
\hline $\mathrm{I}_{\mathrm{b}}$ & 16.7 & 27.5 \\
\hline III & 16.9 & 14.3 \\
\hline
\end{tabular}

${ }^{* *} \mathrm{P}<0.01 ;{ }^{*} \mathrm{P}<0.05$

Figures 


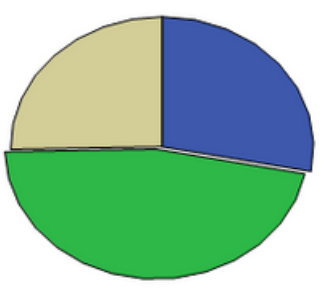

1970-1979

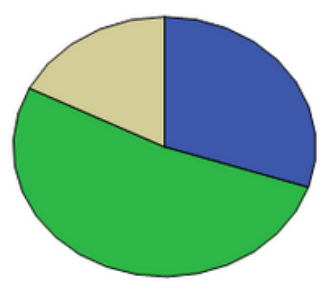

1980-1989

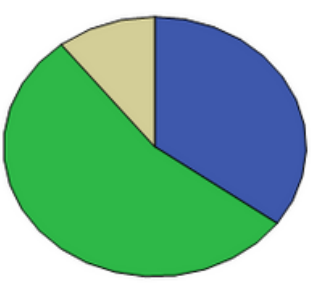

1990-1994

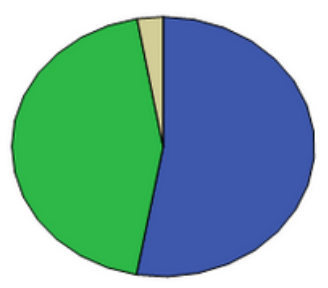

Stage UICC/AJCC 7th

IbllA

IIBIIIAIIIBIIICexcludingT4bN3 IIIC(T4bN3) IV

\section{Figure 1}

Stage distribution of surgically resected esophageal cancer from 1970-2008

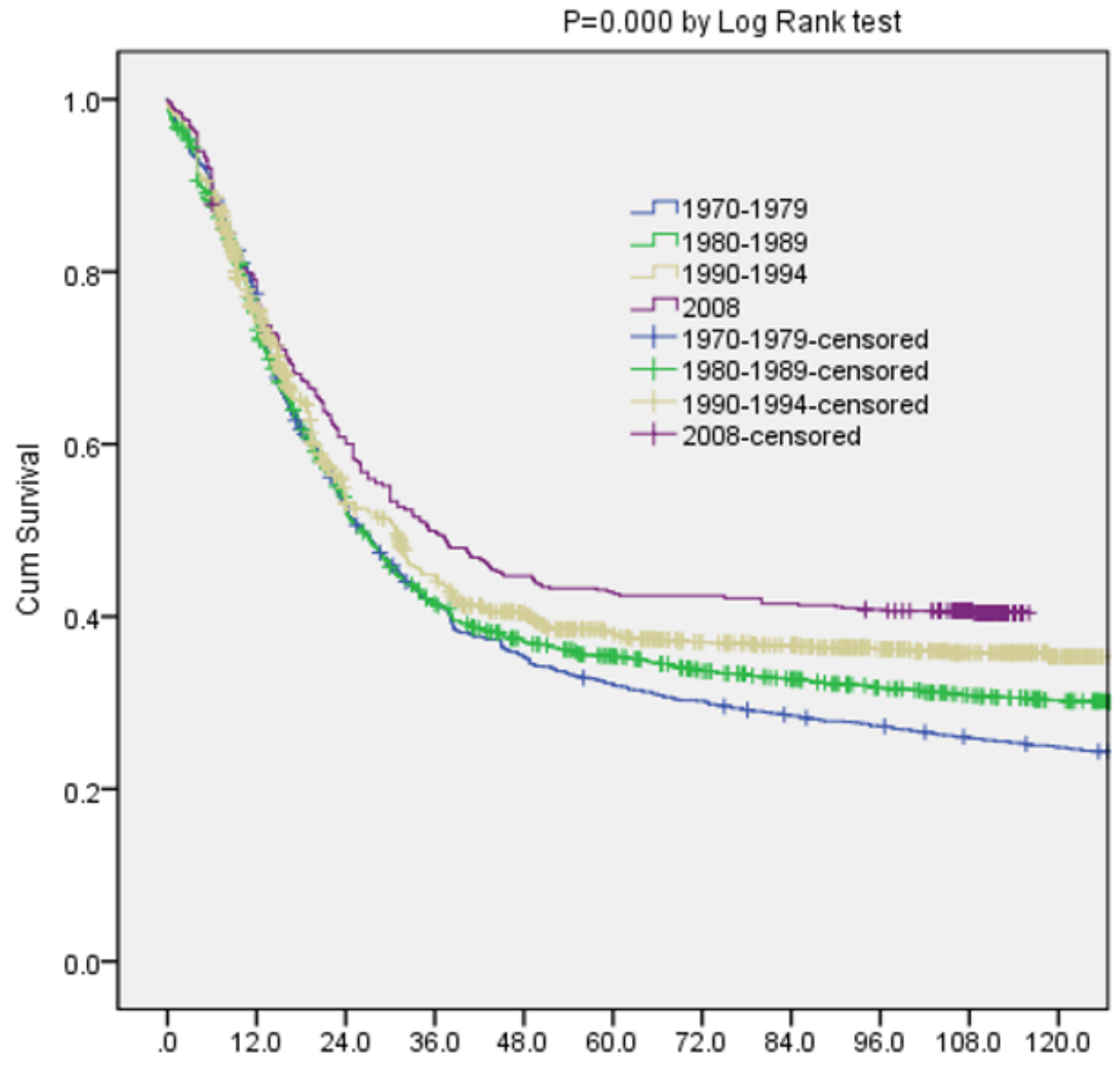

Figure 2

Progress in survival with 5136 surgically resected esophageal cancer cases from 1970-2008 
Esophageal cancer in stage from IB to IIIC, excluding T4b and N3 (UICC/AJCC 7th), Log R ank test $P=0.000$

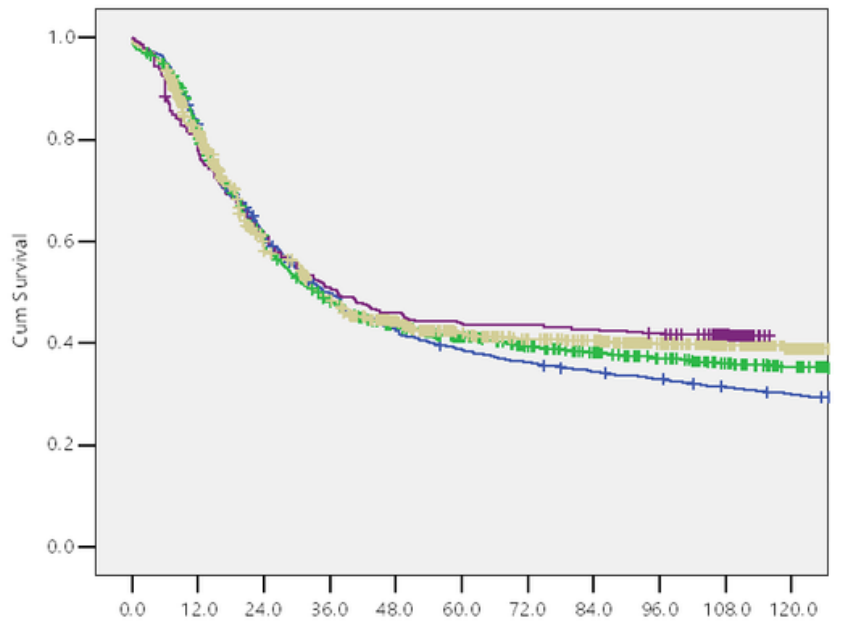

Esophageal cancer in stage from IIIC (T4b and N3) to IV ( UICC /AJCC 7th), Log Rank test P =0.851

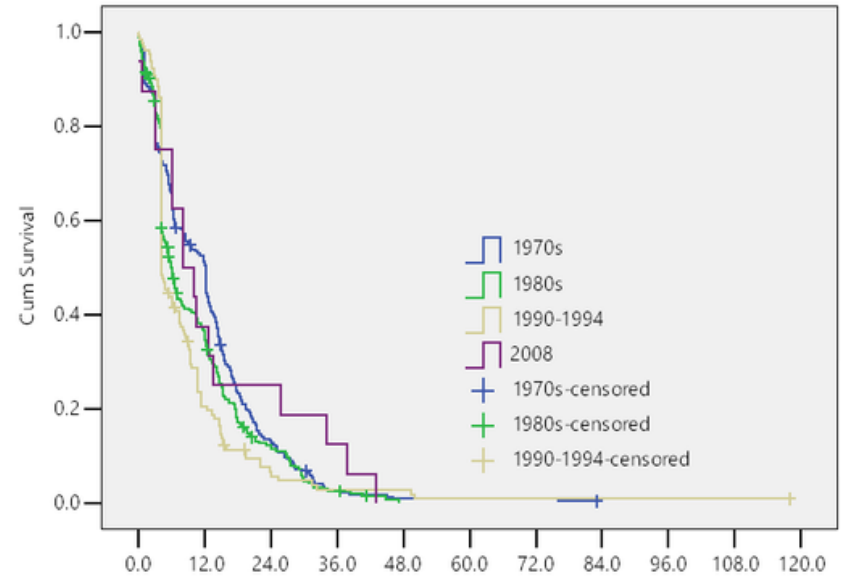

\section{Figure 3}

Stage specific progress in survival with surgically resected esophageal cancer from 1970 to 2008 